\section{RMD Open}

Rheumatic \&

Musculoskeletal Diseases

\title{
Quality indicators for knee and hip osteoarthritis care: a systematic review
} \begin{tabular}{l}
\hline Ilgin G Arslan (D) , ${ }^{1}$ Rianne M Rozendaal, ${ }^{1}$ Marienke van Middelkoop, ${ }^{1}$ \\
Saskia A G Stitzinger, ${ }^{2}$ Maarten-Paul Van de Kerkhove, ${ }^{2,3}$ Vincent M I Voorbrood, ${ }^{1,2}$ \\
Patrick J E Bindels, ${ }^{1}$ Sita M A Bierma-Zeinstra, ${ }^{1,4}$ Dieuwke Schiphof ${ }^{1}$
\end{tabular}
To cite: Arslan IG,

Rozendaal RM

van Middelkoop M, et al. Quality indicators for knee and hip osteoarthritis care: a systematic review. RMD Open 2021;7:e001590. doi:10.1136/ rmdopen-2021-001590

- Additional supplemental material is published online only. To view, please visit the journal online (http://dx.doi.org/10. 1136/rmdopen-2021-001590).

Received 19 January 2021 Accepted 12 May 2021
Check for updates

(c) Author(s) (or their employer(s)) 2021. Re-use permitted under CC BY. Published by BMJ.

${ }^{1}$ General Practice, Erasmus MC University Medical Center, Rotterdam, The Netherlands

${ }^{2}$ General Practice Pallion, Hulst, The Netherlands

${ }^{3}$ Orthopaedics ZorgSaam

Zeeuws-Vlaanderen, Terneuzen, The Netherlands

${ }^{4}$ Department of Orthopaedics,

Erasmus MC University

Medical Center, Rotterdam, The Netherlands

Correspondence to

Ilgin G Arslan;

i.arslan@erasmusmc.n

\section{ABSTRACT}

To provide an overview of quality indicators (QIs) for knee and hip osteoarthritis (KHOA) care and to highlight differences in healthcare settings. A database search was conducted in MEDLINE (PubMed), EMBASE, CINAHL, Web of Science, Cochrane CENTRAL and Google Scholar, OpenGrey and Prospective Trial Register, up to March 2020. Studies developing or adapting existing QI(s) for patients with osteoarthritis were eligible for inclusion. Included studies were categorised into healthcare settings. Qls from included studies were categorised into structure, process and outcome of care. Within these categories, Qls were grouped into themes (eg, physical therapy). A narrative synthesis was used to describe differences and similarities between healthcare settings. We included 20 studies with a total of 196 Qls mostly related to the process of care in different healthcare settings. Few studies included patients' perspectives. Rigorous methods for evidence synthesis to develop Qls were rarely used. Narrative analysis showed differences in QIs between healthcare settings with regard to exercise therapy, weight counselling, referral to laboratory tests and 'do not do' Qls. Differences within the same healthcare setting were identified on radiographic assessment. The heterogeneity in Qls emphasise the necessity to carefully select Qls for KHOA depending on the healthcare setting. This review provides an overview of Qls outlined to their healthcare settings to support healthcare providers and policy makers in selecting the contextually appropriate Qls to validly monitor the quality of $\mathrm{KHOA}$ care. We strongly recommend to review Qls against the most recent guidelines before implementing them into practice.

\section{BACKGROUND}

Osteoarthritis (OA) is one of the leading musculoskeletal causes of global disability, mainly affecting the knees and the hips. ${ }^{1}$ The prevalence has increased worldwide with $32 \%$ between 2005 and 2015 and is expected to increase even more with the ageing of the population and the rising obesity rate. This will become a challenge for the health systems globally. ${ }^{2-4}$

Despite the presence of numerous consistent guidelines for the management of knee and hip OA (KHOA), ${ }^{5-9}$ clinical practice

\section{Key messages}

What is already known about this subject?

- Although the evidence-based recommendations for the management of knee and hip osteoarthritis (KHOA) are internationally similar, clinical practice is context-dependent and therefore varies between countries.

- Previous research has shown that quality indicators (QIs) cannot simply be transferred between countries, due to structural and cultural differences of healthcare systems.

What does this study add?

- This review provides an overview of Qls for KHOA care showing considerable differences between Qls depending on their healthcare settings.

How might this impact on clinical practice or further developments?

- This overview will support healthcare providers and policy makers in selecting the contextually appropriate Qls to validly monitor the quality of care, but we strongly recommend to review the Qls against the most recent guidelines before implementing them into practice.

shows a low consistency with following these recommendations leading to suboptimal care. ${ }^{1011}$ Therefore, routinely monitoring of feedback on quality of care has been made high priority. ${ }^{12}$ Quality indicators (QIs) are measurable elements that can be used to assess the quality of care. These QIs can be related to the characteristics of material and human resources of the healthcare (ie, the structures), activities undertaken in the delivered healthcare (ie, the process) and the changes in health status resulting from the delivered healthcare (ie, the outcomes) ${ }^{13-15}$

Although the evidence-based recommendations for the management of KHOA are internationally similar, clinical practice is context-dependent and therefore varies between countries. In the Netherlands, Scandinavian countries and the UK, the content 
of KHOA treatment depends on the healthcare setting. Non-surgical management of KHOA is largely provided in primary care. For patients who do not respond successfully to this approach, a referral to secondary care for surgical management is indicated. ${ }^{5} 16$ This distinction in healthcare settings is less pronounced in other countries such as the USA, where the first point of contact and access to orthopaedic care strongly depend on patients' health insurance status. ${ }^{17} 18$ Previous research has shown that QIs cannot simply be transferred between countries, due to structural and cultural differences of healthcare systems. ${ }^{19}$ This has led to a variety of QIs for OA care.

Several systematic reviews have focused on QIs for OA in primary care.$^{2021}$ However, an overview of QIs that take into account the differences in healthcare settings and countries is lacking. Such an overview will support healthcare providers and policy makers in selecting the contextually appropriate QIs. This will enable them to validly monitor and provide feedback on the quality of care.

Therefore, the aim of this systematic review was to provide an up-to-date overview of QIs for KHOA in which we outline the healthcare settings and countries for which the QIs have been developed or adapted.

\section{METHODS}

This systematic review was conducted and reported in line with the Preferred Reporting Items for Systematic Reviews and Meta-Analyses statement. ${ }^{22}$ A protocol for conducting this systematic review was developed a priori and is available on request.

\section{Search methods for identification of studies}

An electronic database search was conducted by a trained medical librarian up to March 2020, using MEDLINE (PubMed), EMBASE, CINAHL, Web of Science, Cochrane CENTRAL and Google Scholar databases. For unpublished and ongoing studies, a similar search was conducted in OpenGrey and the Prospective Trial Register database. A range of search terms related to OA (eg, osteoarthrit*, hip, knee) combined with indicator terms (eg, quality*, indicator, process, structure) were used to identify studies. Full details of the search strategy are provided in online supplemental file 1 . The electronic database search involved no restrictions on healthcare setting, country, language, study design and publication status. Reference lists of studies were manually searched recursively until no additional eligible publications were identified.

\section{Criteria for considering studies for this review Type of studies}

Studies about the development of QI(s) and adaptation of existing QI(s) for another context were included (eg, cross-sectional studies, literature reviews and Delphi studies). Reviews that contained QIs which were already included from other studies were excluded, as were conference abstracts and studies written in languages other than English, Scandinavian, Dutch, Turkish and
German. Studies published before January 2000 were excluded, since they may contain QIs that are more likely to be outdated and may therefore include treatment modalities that are no longer recommended. Studies focusing on patients with OA and other diseases (eg, rheumatoid arthritis (RA)) were included if QIs about OA were presented separately.

\section{Type of Qls}

QIs for OA care, either specifically in the knees and hips or OA not related to specific sites, were extracted from the studies. QIs that measure postsurgical healthcare (eg, after joint replacement) were excluded. Various types of individuals (eg, patients, healthcare providers or healthcare managers) could be involved in the adaptation or development process of the QIs, resulting in QIs from various perspectives of stakeholders. ${ }^{13}{ }^{23}$ QIs from all types of perspectives were included in this review.

\section{Data collection and analysis}

All titles and abstracts were double and independently screened for their relevance (IGA plus DS or RR). Fulltexts of potentially eligible studies were gathered and screened again by double independent review to check for their relevance (IGA plus DS or RR). Data from the included studies were extracted into a pretested data extraction form by one reviewer (IGA) and checked by another reviewer (DS or RR). The following data were extracted: general information about the study, healthcare setting, country, target population, involved joints (eg, knee OA, hip OA or any OA), perspective of QI(s), information of testing and implementation of the $\mathrm{QI}(\mathrm{s})$ if this was done in the study and the full QI(s). Furthermore, methods of evidence synthesis and consensus method were extracted. An evidence synthesis using a systematic review and consensus method using a RAND Appropriateness Method or a Delphi method were considered as the most rigorous methods. ${ }^{24}{ }^{25}$ Possible conflict of interest due to funding and non-adherence to the study protocol were extracted and considered as a source of bias. Disagreements in data collection were resolved by consensus and if necessary, by the third reviewer. The extracted QIs were then categorised into three categories according to Donabedian, which conceptualises quality of care through the structures, processes and outcomes of care (online supplemental figure 1).${ }^{13}$ Structure QIs refer to attributes of material and human resources used for providing care (eg, percentage of specialists among all doctors). Process QIs reflect the activities undertaken in the delivered care (eg, percentage of patients who are offered exercise therapy among all patients). Outcome QIs refer to changes in health status as a result of the delivered care (eg, percentage of patients with functional improvement among all patients). Within these three categories, QIs were grouped in themes (eg, QIs for medication, QIs for weight loss, etc). For the purpose of narrative analysis, we categorised studies into healthcare settings, for example, primary care setting or secondary 


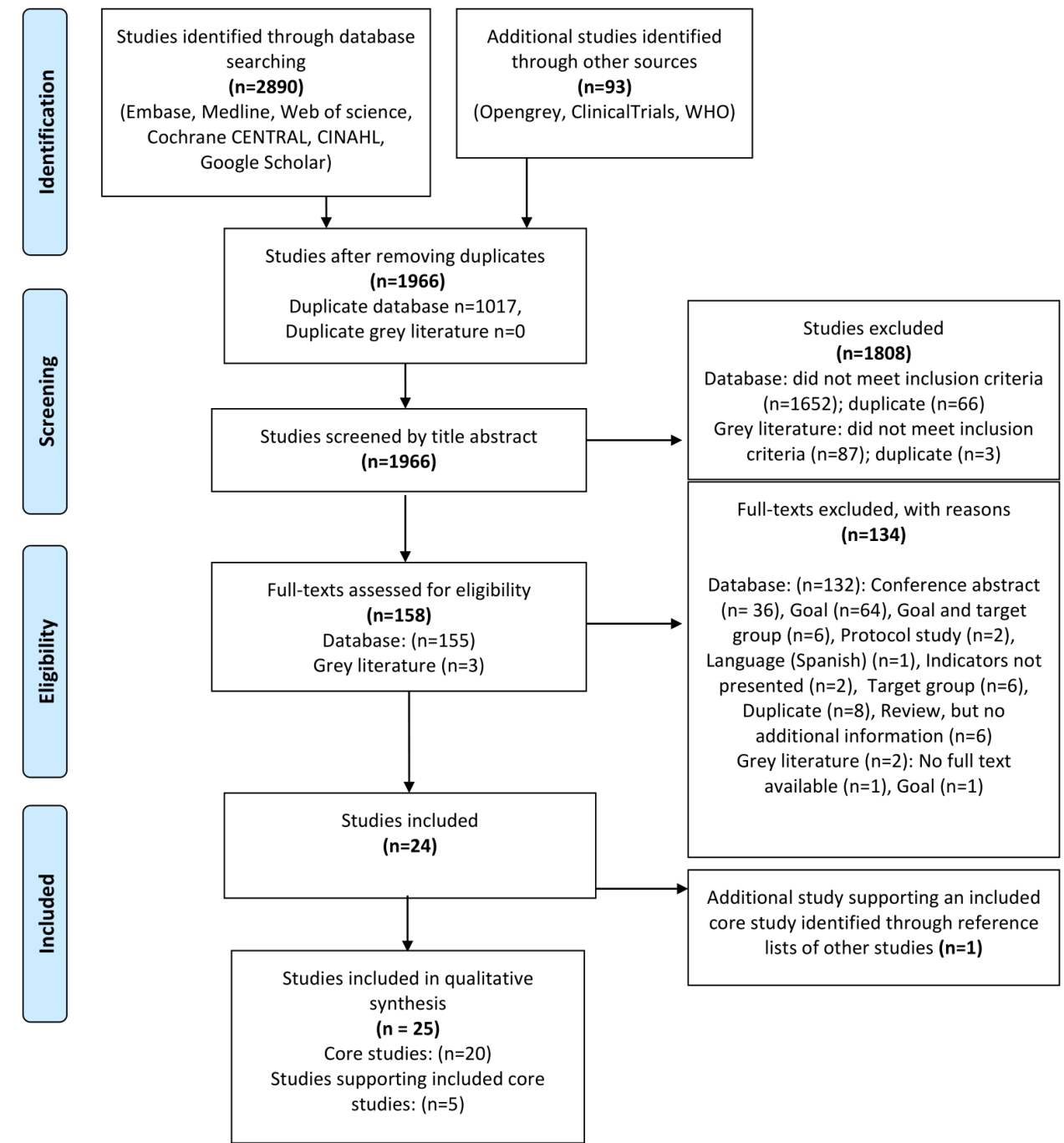

Figure 1 Flow chart for the selection of studies. From: Moher et al. ${ }^{61}$

care setting. Within each category and theme, differences and similarities between the healthcare settings were analysed and summarised. Authors of studies $(n=3$, response rate $=100 \%$ ) were contacted for additional information for the data collection and analysis.

\section{RESULTS}

\section{Results of the search}

The search strategy identified 1966 studies, after removing duplicates (figure 1). After screening on title and abstract, 1808 studies were excluded. The remaining 158 studies were screened on full-texts, of which 24 studies were included. One additional study ${ }^{26}$ was identified through reference lists of included studies. The main reasons for exclusion on full-text are listed in online supplemental file 2. Of the 25 included studies, 5 studies ${ }^{26-30}$ described the methods of other already included studies (ie, core studies) in detail. We did not exclude these studies, but used them as supporting studies for data extraction and analyses, as they contained additional information not reported in the core studies.

\section{Characteristics of the studies included}

Methods of development of Ql(s) or adaptation of existing Ql(s)

The characteristics of the studies included are summarised in table 1 and more detailed in online supplemental file 3 . Only 5 out of 20 studies (25\%) included an evidence synthesis for the QIs using a systematic review. ${ }^{31-35}$ Consensus on QIs during the development phase was mostly done using a (modified) RAND Appropriateness Method $^{19} 31-3436-40$ or Delphi method. ${ }^{41} 42$ The remaining studies used less rigorous methods ${ }^{3543-46}$ or did not specify the methods. ${ }^{478}$ Four studies ${ }^{3644-46}$ tested the reliability of the QIs. Eleven studies ${ }^{19} 3637434446-48$ evaluated the feasibility of QIs in practice and three studies ${ }^{34} 38$ through judgement by an expert panel. Although not every study reported information on conflict of interest, the reviewers judged most of the studies unlikely to have conflict of interest. No study protocols of the studies included were available, hence no judgement about adherence to the protocol could be made. All studies included QIs in the process of care category. Three studies ${ }^{34} 3543$ included QIs in the process and outcome category, and only one study ${ }^{34}$ in all three categories. Information on healthcare 


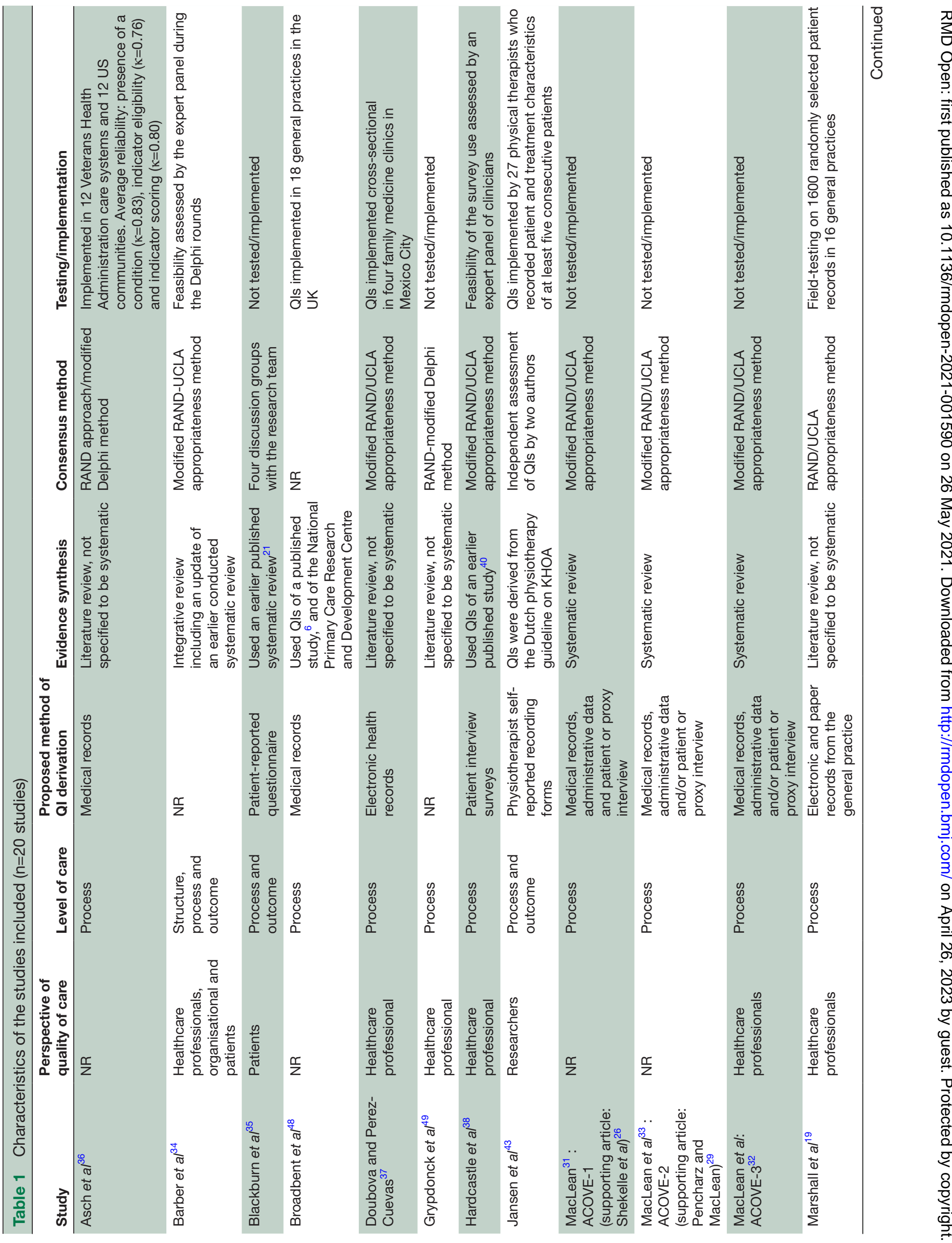




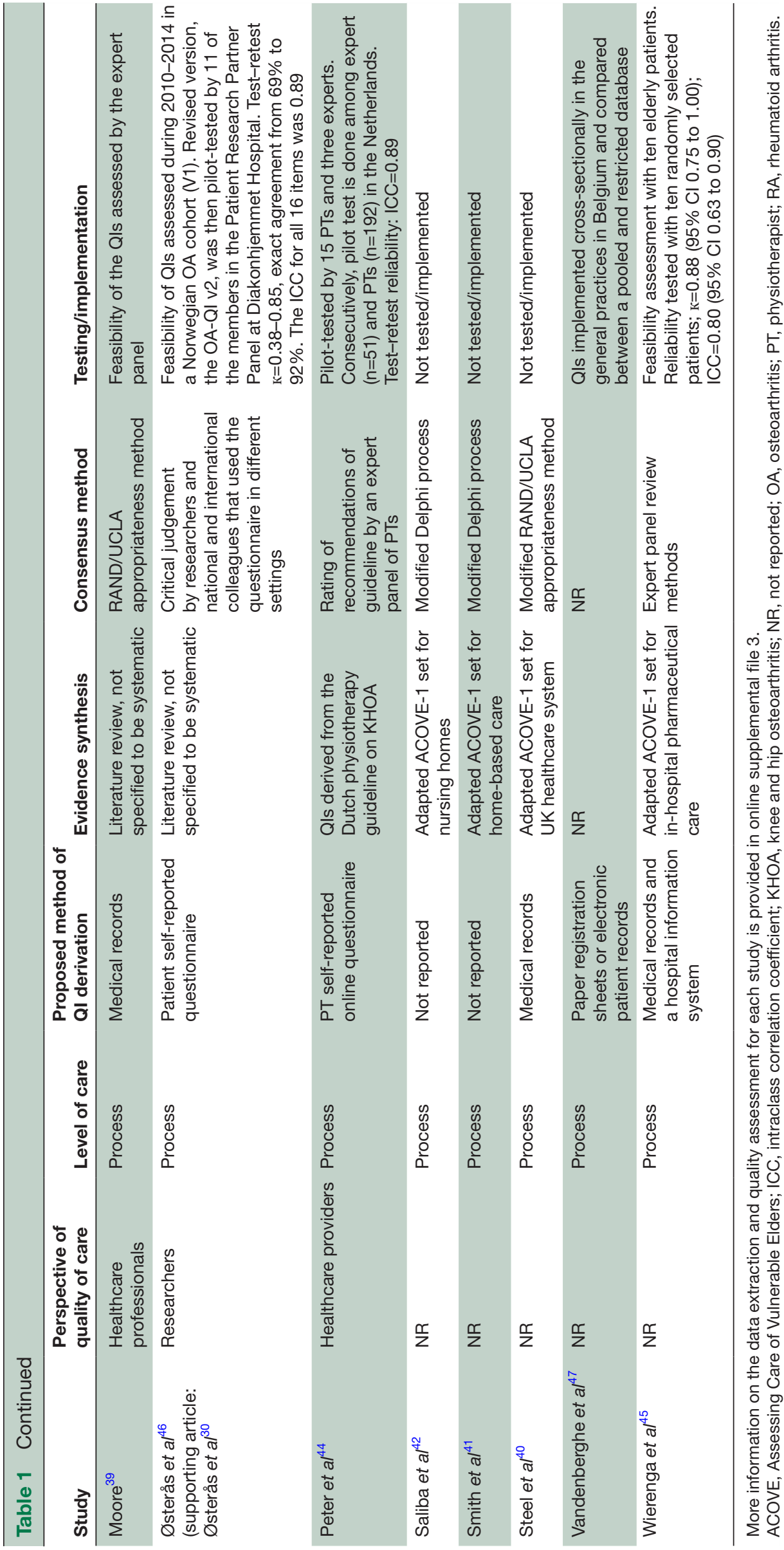


perspectives of the QIs (ie, types of individuals involved with the development/adaptation process of the QIs) was often not reported. Studies that reported the healthcare perspectives for developing QIs or adapting existing QIs mostly involved the perspectives of healthcare professionals ${ }^{193437-394449}$ and researchers, ${ }^{324346}$ and in a few cases the perspectives of patients ${ }^{34} 35$ and healthcare organisations. ${ }^{34}$ QIs were often developed to measure the quality of care with data from paper or electronic records. Some studies ${ }^{35} 38$ developed QIs to measure the quality of care with data from patient or physiotherapist-reported forms $s^{43446}$ or a mixture of patients or proxy interviews and medical records. ${ }^{31-33}$

\section{Healthcare settings}

Studies were categorised into five healthcare settings: primary care $(n=10)$, secondary care $(n=3)$, the entire spectrum of disciplines $(\mathrm{n}=8)$ and centralised intake care $(n=1)$ (table 2). Nine studies 193537404143444748 developed QIs for primary care, mainly on healthcare in general practice and physiotherapy care. Three studies developed QIs for secondary care in the USA, ${ }^{42}$ the Netherlands ${ }^{45}$ and the UK. ${ }^{40}$ We categorised eight studies as targeting the entire spectrum of disciplines since they did not focus on a specific healthcare setting. Five of those ${ }^{31-333639}$ developed QIs for the healthcare system in the USA, of which three ${ }^{31-33}$ developed the Assessing Care of Vulnerable Elders QI set. Of the remaining studies targeting the entire spectrum of disciplines, one study ${ }^{49}$ was conducted in Belgium, one study ${ }^{38}$ focused on UK private households and one study ${ }^{46}$ on the Norwegian healthcare system. Another study ${ }^{34}$ developed QIs for a relatively new and exceptional system in Canada; the centralised intake care. This system pools patients into a single queue, assesses the nature and urgency of referral and prioritises the access to care based on this assessment.

\section{Narrative synthesis}

A total of 196 QIs were derived from the included studies. See online supplemental table 4 for a detailed description of the QIs with the actual wordings as stated in the original studies, grouped by category and theme.

\section{Qls about the structure of care}

With respect to the structure of care, one study ${ }^{34}$ developed three QIs for centralised intake care in Canada concerning the completion of appointments as scheduled, number of specialist providers participating in centralised intake and clinic capacity of the OA teams (table 3 ).

\section{Qls about the process of care}

Regarding the process of care, we identified QIs on 10 different themes (table 4).

History taking and examination ( $n=32$ Qls)

QIs on assessment of functional status and level of pain were most common and focused on all healthcare
Table 2 Included studies $(\mathrm{n}=20)$ categorised according to their healthcare setting

\begin{tabular}{|c|c|c|}
\hline Study & Target population & Country \\
\hline \multicolumn{3}{|c|}{ Primary care } \\
\hline Blackburn et a/ ${ }^{35}$ & $\begin{array}{l}\text { Patients with OA in } \\
\text { primary care setting }\end{array}$ & UK \\
\hline Broadbent et al ${ }^{48}$ & $\begin{array}{l}\text { Patients with } \mathrm{OA} \text { in } \\
\text { general practice }\end{array}$ & UK \\
\hline $\begin{array}{l}\text { Doubova and Perez- } \\
\text { Cuevas }^{37}\end{array}$ & $\begin{array}{l}\text { Patients with KHOA } \\
\text { aged } \geq 19 \text { in family } \\
\text { medicine }\end{array}$ & Mexico \\
\hline Jansen et $a l^{43}$ & $\begin{array}{l}\text { Patients with } \mathrm{KHOA} \text { in } \\
\text { PT care }\end{array}$ & The Netherlands \\
\hline Marshall et $a l^{19}$ & $\begin{array}{l}\text { Patients with } O A \text { in } \\
\text { general practice }\end{array}$ & UK \\
\hline Peter et $a l^{44}$ & $\begin{array}{l}\text { Patients with } \mathrm{KHOA} \text { in } \\
\text { PT care }\end{array}$ & The Netherlands \\
\hline Smith et $a l^{41}$ & $\begin{array}{l}\text { Housebound elderly } \\
\text { patients in home- } \\
\text { based primary care }\end{array}$ & USA \\
\hline Steel et $a l^{\star \star 40}$ & $\begin{array}{l}\text { People aged } 65 \text { and } \\
\text { with OA in primary } \\
\text { and secondary care }\end{array}$ & UK \\
\hline Vandenberghe et al ${ }^{47}$ & $\begin{array}{l}\text { Patients with } O A \text { of } \\
\text { aged } \geq 60 \text { in general } \\
\text { practice }\end{array}$ & Belgium \\
\hline \multicolumn{3}{|c|}{ Secondary care } \\
\hline Saliba et $a l^{42}$ & $\begin{array}{l}\text { Institutionalised } \\
\text { vulnerable elderly with } \\
\text { OA in nursing homes }\end{array}$ & USA \\
\hline Steel et $a l^{\star \star 40}$ & $\begin{array}{l}\text { People aged } 65 \text { and } \\
\text { with OA in primary } \\
\text { and secondary care }\end{array}$ & UK \\
\hline Wierenga et $a l^{45}$ & $\begin{array}{l}\text { Elderly hospitalised } \\
\text { patients with OA } \\
\text { from in-hospital } \\
\text { pharmaceutical care }\end{array}$ & The Netherlands \\
\hline \multicolumn{3}{|c|}{ The entire spectrum of disciplines } \\
\hline Asch et $a l^{36}$ & $\begin{array}{l}\text { Patients of outpatient } \\
\text { and inpatient care } \\
\text { for acute and } \\
\text { chronic conditions } \\
\text { and preventive care } \\
\text { (including OA) }\end{array}$ & USA \\
\hline Grypdonck et al ${ }^{49}$ & $\begin{array}{l}\text { Patients with knee } \\
\text { OA across the } \\
\text { entire spectrum of } \\
\text { disciplines }\end{array}$ & $\begin{array}{l}\text { No country } \\
\text { specified }\end{array}$ \\
\hline Hardcastle et $a^{38}$ & $\begin{array}{l}\text { People with OA aged } \\
\geq 50 \text { living in private } \\
\text { households }\end{array}$ & UK \\
\hline MacLean ${ }^{31}$ & $\begin{array}{l}\text { Vulnerable elderly } \\
\text { with OA }\end{array}$ & USA \\
\hline MacLean et $a l^{33}$ & Patients with OA & USA \\
\hline MacLean et $\left.a\right|^{32}$ & $\begin{array}{l}\text { Vulnerable elderly } \\
\text { with OA }\end{array}$ & USA \\
\hline Moore 39 & Patients with OA & USA \\
\hline
\end{tabular}




\begin{tabular}{lll}
\hline Table 2 Continued & \\
\hline Study & Target population & Country \\
\hline Osterås et al $^{46}$ & Patients with OA & Norway \\
\multicolumn{1}{c}{ Centralised intake care system } & \\
Barber et al ${ }^{34}$ & $\begin{array}{l}\text { Patients with RA and// Canada } \\
\text { or OA in centralised } \\
\text { intake care system }\end{array}$ & \\
\hline
\end{tabular}

* Steel et $a{ }^{40}$ is listed twice in the table, as it focuses on 'primary care' and 'secondary care'.

KHOA, knee and hip osteoarthritis; OA, osteoarthritis; PT, physiotherapy; RA, rheumatoid arthritis.

settings, except for centralised intake care. QIs on assessment for assistive devices, appliances and aids, and radiographic assessment also focused on the entire spectrum of disciplines, except for centralised intake care. Differences were seen in the indication for radiographic assessment; from offering a radiography to patients with incident hip OA to only offering a radiograph to patients with worsening complaints or patients who seem resistant to conservative treatment. QIs on the diagnostic aspiration of the joint and examination of joint before drug use were less common and focused on the US only. QIs relating to history taking and health assessment to evaluate the given treatment were mainly described for (physiotherapy) primary care settings in Europe.

\section{Education and information ( $n=22 \mathrm{QIs}$ )}

QIs on this theme related to information on the pathology of OA, treatment options and self-management and were similar between countries. Most QIs on this theme were developed for primary care (physiotherapy) in the Netherlands, but least for secondary care and healthcare in the US.

\section{Exercise therapy ( $n=25$ Qls)}

QIs regarding exercise therapy were mostly developed for primary care on recommending and prescribing physiotherapy or specific exercises and were similar between countries. Three QIs focusing on the entire spectrum of disciplines were found regarding the frequency and regular evaluations of exercise therapy sessions, and regarding tailoring exercise therapy to patients goals.

\section{Weight counselling $(n=7)$}

QIs for advice on weight loss were developed for primary care and the entire spectrum of disciplines. Body mass index (BMI) threshold and frequency for advising patients to lose weight differed between QIs for the entire spectrum of disciplines in the USA and QIs for family medicine in Mexico $\left(>25 \mathrm{~kg} / \mathrm{m}^{2} \mathrm{vs}>27 \mathrm{~kg} / \mathrm{m}^{2}\right.$, and at least once in 2 years vs annually).

\section{'Do not do' Qls (n=3)}

Two QIs for primary care (physiotherapy) in the Netherlands focused on recommending against massage and physical modalities other than Transcutaneous Electrical Nerve Stimulation. One QI for the entire spectrum of disciplines focused on not prescribing a brace for people with knee OA, except for patients with unicompartmental knee $\mathrm{OA}$ with axial deviation.

\section{Pharmacological treatment $(n=51)$}

Most of the pharmacological treatment QIs were developed for primary care. These QIs were consistent in their content and covered: (1) the use of paracetamol as first-line pharmacological therapy, (2) prescribing a trial of maximum-dose paracetamol before changing to a different oral agent, (3) non-steroidal anti-inflammatory drugs (NSAIDs) prescription, (4) NSAID prescription concomitant with either misoprostol or proton-pump inhibitor and (5) informing/screening patients about the risks of medication use. One additional QIs for the entire spectrum of disciplines in Norway focused on the indication of injections. ${ }^{46}$ Four QIs focused on not using several drug types, mainly focusing on primary care. One QI covered not using strong opioids and one QI not using chondroitin and glucosamine-chondroitin. ${ }^{49}$ A Norwegian study ${ }^{46}$ formulated a QI that offering stronger pain killers in OA patients (eg, co-proxamol, co-dydramol, tramadol, co-codamol, dihydrocodeine, codeine) in case of no sufficient pain relief by paracetamol reflects better quality of care.

\section{Referrals $(n=26)$}

Four QIs were found regarding the referral of patients to exercise therapy/programmes/activities in all studies included in this study, except in studies focusing on Mexico and the USA. From the three QIs that focused on referral for weight loss services, only one ${ }^{33}$ defined a specific threshold for BMI for the referral to weight loss

Table 3 Quality indicators on structure of care $(n=3)$

\begin{tabular}{|c|c|c|}
\hline Theme & Subtheme (number of QIs) & Healthcare setting and country \\
\hline Musculoskeletal appointments & $\begin{array}{l}\text { Musculoskeletal appointments completed as scheduled } \\
(\mathrm{n}=1)\end{array}$ & Centralised intake care system in Canada ${ }^{34}$ \\
\hline Healthcare providers involved & $\begin{array}{l}\text { Specialist providers participating in centralised intake } \\
(n=1)\end{array}$ & Centralised intake care system in Canada ${ }^{34}$ \\
\hline Estimation of clinic capacity & $\begin{array}{l}\text { Ratio of patient flow to estimated clinic capacity of OA } \\
\text { teams participating in centralised intake }(n=1)\end{array}$ & Centralised intake care system in Canada ${ }^{34}$ \\
\hline
\end{tabular}

$\mathrm{OA}$, osteoarthritis; QI, quality indicator. 
Table 4 Quality indicators on process of care $(n=182)$

\begin{tabular}{|c|c|c|}
\hline Theme & Subtheme (number of QIs) & Healthcare setting and country \\
\hline \multirow[t]{4}{*}{$\begin{array}{l}\text { History taking and } \\
\text { examination }(n=32)\end{array}$} & Regular assessment of functional status and pain $(n=9)$ & $\begin{array}{l}\text { Primary care in the UK, USA and Norway. }{ }^{40414648} \\
\text { Secondary care in the UK and USA. }{ }^{4042} \\
\text { The entire spectrum of disciplines in the USA. }{ }^{31-33}\end{array}$ \\
\hline & Radiographic assessment $(n=3)$ & $\begin{array}{l}\text { The entire spectrum of disciplines in the USA and one } \\
\text { study with unspecified country. } 33949\end{array}$ \\
\hline & Inventory of health-related problems $(n=4)$ & $\begin{array}{l}\text { Primary care; PT care in the Netherlands. }{ }^{44} \\
\text { The entire spectrum of disciplines in Norway. }{ }^{46}\end{array}$ \\
\hline & Examination of joint before drug treatment $(n=2)$ & $\begin{array}{l}\text { Secondary care in the USA. } \\
\text { The entire spectrum of disciplines in the USA. }\end{array}$ \\
\hline \multirow{4}{*}{$\begin{array}{l}\text { Education and information } \\
(\mathrm{n}=22)\end{array}$} & $\begin{array}{l}\text { Information concerning joint protection and the use of } \\
\text { aids }(n=1)\end{array}$ & Primary care; PT care in the Netherlands ${ }^{44}$ \\
\hline & Advise about medication $(n=1)$ & Primary care in the $\mathrm{UK}^{35}$ \\
\hline & $\begin{array}{l}\text { Information concerning pathology of } O A \text {, treatment } \\
\text { and self-management formulated in general }(n=10)\end{array}$ & $\begin{array}{l}\text { Primary care in the UK. } .^{35} 4048 \\
\text { Secondary care in the UK. } \\
\text { The entire spectrum of disciplines in the } \\
\text { USA, Norway and one study with unspecified } \\
\text { country. }\end{array}$ \\
\hline & $\begin{array}{l}\text { Information regarding resources and tools while } \\
\text { waiting for an appointment }(n=1)\end{array}$ & Centralised intake care system in Canada ${ }^{34}$ \\
\hline \multirow{2}{*}{ Exercise therapy $(n=25)$} & $\begin{array}{l}\text { Recommendation of exercise therapy formulated in } \\
\text { general }(n=2)\end{array}$ & The entire spectrum of disciplines in the USA ${ }^{36} 39$ \\
\hline & $\begin{array}{l}\text { Combining exercise therapy with education/self- } \\
\text { management interventions, frequency and evaluation, } \\
\text { and tailoring exercise therapy to patients' goals }(n=4)\end{array}$ & $\begin{array}{l}\text { The entire spectrum of disciplines, country not } \\
\text { specified }^{49}\end{array}$ \\
\hline Weight counselling $(n=7)$ & Advice about body weight and joint pain $(n=7)$ & $\begin{array}{l}\text { Primary care in the UK and Mexico. } 3537 \\
\text { The entire spectrum of disciplines in the } \\
\text { USA, Norway and one study with unspecified } \\
\text { country. }{ }^{33} 394649\end{array}$ \\
\hline 'Do not do' Qls ( $n=3)$ & $\begin{array}{l}\text { No massage therapy, no prescription of a brace and no } \\
\text { physical modalities other than TENS }(n=3)\end{array}$ & $\begin{array}{l}\text { Primary care; PT care in the Netherlands. }{ }^{43} \\
\text { The entire spectrum of disciplines; country not } \\
\text { specified. }{ }^{49}\end{array}$ \\
\hline
\end{tabular}


Table 4 Continued

\begin{tabular}{ll}
\hline Theme & Subtheme (number of QIs) \\
\hline $\begin{array}{l}\text { Pharmacological treatment } \\
(n=51)\end{array}$ & $\begin{array}{l}\text { Paracetamol as first-line pharmacological therapy } \\
(n=16)\end{array}$
\end{tabular}
$(\mathrm{n}=51)$ $(n=16)$

Trial of maximum-dose acetaminophen before changing from acetaminophen to different oral agent $(n=7)$

Prescription of NSAIDs and concomitant with either misoprostol or proton-pump inhibitor $(n=15)$

Informing patients about risks of medication use and screening for side effects $(n=8)$

Injection $(\mathrm{n}=1)$

No medication use of several drug types, that is, chondroitin and glucosamine-chondroitin and strong pain killers such as opioids $(n=4)$

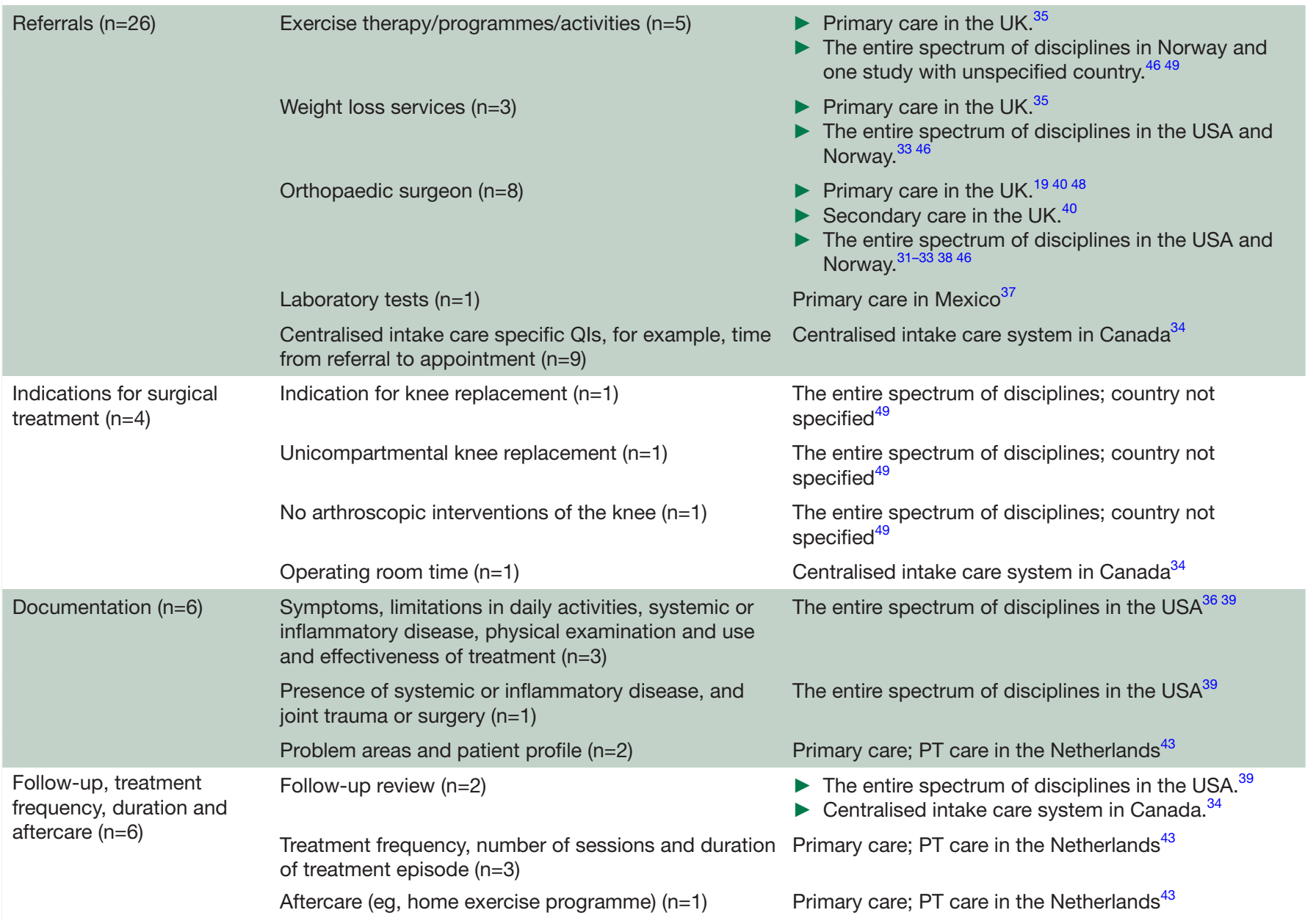

NSAID, non-steroidal anti-inflammatory drug; OA, osteoarthritis; PT, physiotherapy; QI, quality indicator; TENS, transcutaneous electrical nerve stimulation.

services (US healthcare). QIs regarding the referral to an orthopaedic surgeon when patients do not respond sufficiently to non-surgical therapy were similar in all studies.

\section{Healthcare setting and country}

- Primary care in the USA, UK, Belgium and Mexico. ${ }^{19} 3740414748$

- Secondary care in the Netherlands, UK and USA. ${ }^{40} 4245$

- The entire spectrum of disciplines in the USA UK, Norway and one study with unspecified country. ${ }^{31-33} 3638394649$

- Primary care in the UK and USA. ${ }^{404148}$

- Secondary care in the USA, UK and the Netherlands. ${ }^{40} 4245$

- The entire spectrum of disciplines in the USA. ${ }^{31} 33$

- Primary care in the UK, Belgium and Mexico. ${ }^{19} 374748$

- The entire spectrum of discipline in the USA and one study with unspecified country. ${ }^{313249}$

- Primary care in the USA and UK. ${ }^{41} 48$

- The entire spectrum of disciplines in the USA and Norway. ${ }^{31} 3246$

The entire spectrum of disciplines in Norway ${ }^{46}$

- Primary care in Belgium. ${ }^{47}$

- The entire spectrum of disciplines in the USA and Norway. ${ }^{46} 49$

- Primary care in the UK. ${ }^{35}$

The entire spectrum of disciplines in Norway and

Primary care in the UK. ${ }^{35}$

The entire spectrum of disciplines in the USA and

Secondary care in the UK.

Primary care in Mexico ${ }^{37}$

Centralised intake care system in Canada ${ }^{34}$

The entire spectrum of disciplines; country not ecified ${ }^{49}$

The entire spectrum of disciplines; country not pecified ${ }^{4}$ specified $^{49}$

entralised intake care system in Canada

The entire spectrum of disciplines in the USA ${ }^{36} 39$

The entire spectrum of disciplines in the USA ${ }^{39}$

Primary care; PT care in the Netherlands ${ }^{43}$

- The entire spectrum of disciplines in the USA. ${ }^{39}$

Centralised intake care system in Canada. ${ }^{34}$

Primary care; PT care in the Netherlands ${ }^{43}$
There was only one QI for family medicine in Mexico regarding referral to laboratory test to detect possible

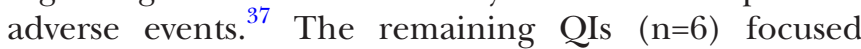


on centralised intake care in Canada, ${ }^{34}$ for example, regarding the agreement of centralised intake suspected diagnosis of severe OA cases versus confirmed diagnosis of severe OA.

\section{Indication of surgery $(n=4)$}

Only two studies developed QIs on the indication for surgical treatment. One study for the entire spectrum of disciplines ${ }^{49}$ developed QIs for indications for different types of surgical treatments for knee OA (ie, joint replacement and arthroscopic interventions) and one study ${ }^{34}$ for centralised intake care system in Canada regarding operating room time. QIs regarding indications for surgical treatment for hip OA are lacking. Remarkably, studies that focused on secondary care ${ }^{40} 45$ did not develop QIs for the indications for surgical treatment.

\section{Documentation $(n=6)$}

Six QIs were found on documentation of information on measures from physical examination for the entire spectrum of disciplines in the USA ${ }^{36} 39$ and on patients' characteristics for primary care (physiotherapy) in the Netherlands. ${ }^{43}$

\section{Treatment frequency, duration, follow-up and aftercare $(n=6)$}

Although not all QIs on this theme defined a specific threshold, three QIs for primary care (physiotherapy) in the Netherlands and one for the entire spectrum of disciplines in the US healthcare specified a threshold for treatment frequency ( $<12$ consultations), duration $(<6$ weeks) and follow-up (every 6 weeks). The study on primary care (physiotherapy) in the Netherlands ${ }^{43}$ was also the only one that developed a QI for aftercare, for example, regarding home exercise programmes.

\section{Qls at outcome level of care}

QIs at outcome level of care included experiences and satisfaction with healthcare $(n=6)$, pain and functional capacity $(n=3)$ and achievement of treatment goals $(n=1)$ (table 5). The QIs on satisfaction and experiences of healthcare providers and patients were mostly developed for centralised intake care in Canada. The QIs on the other themes were developed for primary care (physiotherapy) in the Netherlands. ${ }^{43}$ For most of the QIs on outcome level of care, the threshold reflecting high or low quality of care was not specified (eg, QI: 'the extent to which the treatment goals were achieved $\left.{ }^{43}\right)$.

\section{DISCUSSION}

This systematic review provides an overview of 20 studies including a total number of 196 QIs for KHOA care for a variety of healthcare settings. Rigorous methods for evidence synthesis to develop QIs were rarely used in the included studies. Adequate reporting on the perspective of healthcare, the proposed method of measurement (eg, medical records) and threshold of the QIs was lacking. QIs were mainly developed from the perspective of healthcare professionals and researchers, while a patient perspective is limited. Narrative analysis showed that most healthcare settings and countries contain QIs on the following themes with largely similar content: (1) examination of functional status and pain, (2) education and information, (3) exercise therapy, (4) referral to exercise therapy/programmes/activities (5) and pharmacological treatment regarding paracetamol, NSAID and risks of medication use. For example, regarding the use of paracetamol as first-line pharmacological therapy and prescribing a trial of maximum-dose paracetamol before changing to a different oral agent. Some differences in the content of QIs occur due to the healthcare system, that is, QIs about exercise therapy, weight counselling, referral to laboratory tests and 'do not do' QIs (mainly described for physiotherapy care in the Netherlands). Nevertheless, differences in the content of QIs occurred within the same healthcare setting with regard to indications for radiographic assessment of the joint.

Studies in the current review included mostly QIs that were related to the process of care. An explanation therefore could be that the studies included developed QIs or adapted existing QIs for quality of care improvement purposes. Process measures offer a roadmap for improving care or list the actions required to eventually improve outcomes for quality improvement purposes. In contrast, outcome measures are mainly developed for public reporting and accountability purposes through feedback on quality of care in order to stimulate quality improvement rather than specific actions to improve the quality of care. ${ }^{50}$ Another explanation might be that outcome measures in OA care mainly focus on reduction in pain and functional improvement. These outcome measures are not easy to capture within daily practice as a process of care. In contrast, for example, blood tests to measure disease activity of RA are captured as a process

Table 5 Quality indicators on outcome of care $(n=11)$

\begin{tabular}{|c|c|c|}
\hline Theme & Subtheme (number of QIs) & Healthcare setting and country \\
\hline \multirow[t]{2}{*}{$\begin{array}{l}\text { Experiences and satisfaction with } \\
\text { healthcare }(n=6)\end{array}$} & $\begin{array}{l}\text { Healthcare providers' and patients' experiences } \\
(n=4)\end{array}$ & Centralised intake care system in Canada ${ }^{34}$ \\
\hline & Patients' satisfaction $(n=2)$ & $\begin{array}{l}\text { Primary care in the UK and PT care in the } \\
\text { Netherlands }{ }^{35} 43\end{array}$ \\
\hline Pain and functional capacity $(n=4)$ & Level of pain and functional capacity $(n=3)$ & Primary care; PT care in the Netherlands ${ }^{43}$ \\
\hline Achievement of treatment goals $(n=1)$ & $\begin{array}{l}\text { The extent to which the treatment goals were } \\
\text { achieved }(n=1)\end{array}$ & Primary care; PT care in the Netherlands ${ }^{43}$ \\
\hline
\end{tabular}

PT, physiotherapy; QI, quality indicator. 
of care for patients with RA, which makes it easier to evaluate this measure as an outcome of care. However, the low number of QIs on structure of care remains unclear. Most QIs on outcome level were developed in the physiotherapy care in the Netherlands. These QIs are derived from the Dutch KHOA guidelines for physiotherapy with great focus on the outcomes of therapy.

This study identified differences within themes of QIs, which can be explained by differences between healthcare settings and countries. First, QIs for physiotherapy care in the Netherlands strongly focused on inventory of health-related problems, education and information, and exercise therapy. This is likely explained by the fact that the management of KHOA in physiotherapy care focuses on non-surgical and non-pharmacological management, containing the interventions these QIs include. Also, these QIs have been formulated in more detail, for example, regarding the specific content of selfmanagement (eg, coping style with health problems). This may be due to the great focus on informing, advising and self-management in the Dutch KHOA guidelines for physiotherapy where these QIs are derived from. Second, QIs for centralised intake care in Canada ${ }^{34}$ is a healthcare setting that aims to prioritise access to care for patients with KHOA with a great focus on the structure of care. This is reflected by the fact that this study was the only one that included structure QIs. Third, QIs on pharmacological treatment were mainly described in studies about primary care setting. This is likely explained by the fact that primary care focuses on non-surgical treatment, containing pharmacological and non-pharmacological therapy, compared with secondary care. Altogether, the differences that this systematic review identified between QIs emphasise the heterogeneity of QIs for KHOA depending on the healthcare setting.

This systematic review did however identify differences which could not be fully explained by healthcare setting. These QIs concerned laboratory test in case of an NSAID prescription for $\geq 6$ months to detect possible adverse events, a BMI threshold and frequency for advising patients to lose weight, and specific indications for radiographic assessment for KHOA. For example, two studies focusing on healthcare in the US described different indications, one describing that patients with incident hip OA should be offered an anteroposterior radiograph $^{39}$ and another describing that patients with worsening complaints of KHOA accompanied by progressive decrease in activities should receive a radiograph within 3 months. ${ }^{33}$ However, this difference might be explained by the year of the study, which may indicate how up-todate of the content of the QI is. The study describing that patients with worsening complaints should receive a radiograph ${ }^{33}$ was published more recently (ie, 2004) and is in line with the current evidence ${ }^{51}$ compared with the study that recommends a radiograph for patients with incident hip $\mathrm{OA}^{39}$ (ie, 2000). Another remarkable finding was that QIs on pharmacological treatment are consistent in the use of paracetamol as first-line pharmacological therapy and prescribing NSAIDs after a trial of maximum-dose paracetamol. However, recent guidelines do not recommend the use of paracetamol and the use of topical NSAIDs instead of paracetamol is strongly recommended. ${ }^{8}$ QIs about pharmacological treatment might be mostly influenced by guidelines and need to be up-to-date with the most recent guidelines. In addition, more agreement and uniformly formulated QIs within similar healthcare settings on these themes are needed to enhance uniform requirements for quality of care.

Of some frequently used treatments for OA, very little is described in QIs. For example, only one of 196 identified QIs focused on the prescription of opioids. Furthermore, QIs regarding injections, not prescribing chondroitin and glucosamine-chondroitin and indications for surgical treatment for hip OA are scarce. Also, there is currently an overuse of imaging to diagnose KHOA, while guidelines recommend to diagnose KHOA clinically. ${ }^{5-7}$ 52 However, none of the studies focusing on primary care included QIs on imaging, while in these countries, the diagnosis and management of OA is mainly provided in primary care with general practitioners as the gatekeepers. Supplementing current QI sets, especially for primary care, with QIs on imaging may be helpful in reducing the overuse of imaging for the diagnosis of OA. In addition, although evidence shows the benefits of treatment tailored to patients' preferences for satisfaction with treatment, uptake, and effectiveness of treatment, ${ }^{53}$ QIs relating to patients' preferences are scarce. QIs mainly represented the perspective of healthcare professionals, while the perspectives of patients are just as important, ${ }^{54}$ as they are the service users of healthcare ${ }^{55}$ Hence, future research on development of QIs on these themes is needed.

This systematic review was restricted to studies that developed QIs or adapted existing QIs. A previously published review ${ }^{21}$ on QIs for primary care for OA also included studies that evaluated the feasibility and reliability of existing QIs. We did not include these studies, while it may provide valuable information for the application of the QIs. We recommend for future research to evaluate implementation studies on the feasibility, validity and reliability of QI-sets in this review to add more guidance for the use of the QIs. Another limitation of this study may be that our literature search was not restricted on the date of publication, since our aim was to provide an extensive overview of the evidence. However, QIs from old studies may no longer apply to the current healthcare. Another limitation may be that we did not assess the quality of the included studies due to the absence of a quality assessment tool for studies developing QIs. To compensate the lack of such a tool, we presented the evidence synthesis and consensus method used in the included studies, which provided some information about the quality of the studies. Furthermore, we evaluated QIs from the literature using the Donabedian structure-process-outcome framework. However, 
other healthcare frameworks could have yielded other differences between healthcare settings and within the same healthcare settings. For example, the framework put forth by the Institute of Medicine, including the following six domains of quality of care: safe, effective, patient-centred, timely, efficient and equitable.$^{56}$ Finally, our literature search did not include a search for websites for QIs in current use in quality or pay for performance programmes for specific hospitals or healthcare systems (eg, US National Quality Forum ${ }^{57}$ and UK National Institute for Health \& Clinical Excellence ${ }^{58}$ ).

Previously published reviews ${ }^{20} 2134355960$ focused on QIs specific healthcare settings (eg, primary care and centralised intake care systems), or perspectives (eg, patients' perspectives). To our knowledge, this is the first systematic review that provides a comprehensive overview of QIs for KHOA outlining the differences and similarities between healthcare settings. This demonstrates the importance of selecting the contextually appropriate QIs to validly monitor the quality of care for KHOA.

\section{CONCLUSION}

This review showed considerable differences between QIs depending on their healthcare settings. Furthermore, this review provides an overview of QIs outlined to their healthcare settings to support healthcare providers and policy makers in selecting the contextually appropriate QIs to validly monitor the quality of care for KHOA. However, we strongly recommend to review QIs against the most recent guidelines before implementing them into practice, especially QIs regarding pharmacological treatment. Furthermore, more adequate reporting of studies, rigorous methods of development of QIs and a greater variety of perspectives of stakeholders is needed. In addition, more uniformly formulated within the same healthcare settings and on several areas and up-to-date QIs are needed.

Acknowledgements We would like to acknowledge Wichor Bramer, Biomedical Information Specialist, Erasmus MC, for his useful and excellent work in conducting the electronic database search. In addition, we sincerely thank the reviewers and editors for their valuable comments.

Contributors All authors developed the first idea for the review. IGA, RMR and DS carried out the data collection and analysis. All authors gave their comments on the first and final version of this manuscript.

Funding This work was partly supported by the Dutch health insurance company CZ.

Disclaimer The funders had no role in the study design, data collection, data analysis, nor in the interpretation and reporting of results.

Competing interests None declared.

Patient consent for publication Not required.

Provenance and peer review Not commissioned; externally peer reviewed.

Open access This is an open access article distributed in accordance with the Creative Commons Attribution 4.0 Unported (CC BY 4.0) license, which permits others to copy, redistribute, remix, transform and build upon this work for any purpose, provided the original work is properly cited, a link to the licence is given, and indication of whether changes were made. See: https://creativecommons.org/ licenses/by/4.0/.

ORCID iD

Ilgin G Arslan http://orcid.org/0000-0003-2046-6177
REFERENCES

1 World Health Organization. Musculoskeletal conditions, 2018. Available: http://www.who.int/mediacentre/factsheets/ musculoskeletal/en/ [Accessed 19 Jun 2018]

2 Cross M, Smith E, Hoy D, et al. The global burden of hip and knee osteoarthritis: estimates from the global burden of disease 2010 study. Ann Rheum Dis 2014;73:1323-30.

3 World Health Organization. Musculoskeletal conditions, 2020. Available: https://www.who.int/news-room/fact-sheets/detail/ musculoskeletal-conditions [Accessed 21 Feb 2020].

4 GBD 2017 Disease and Injury Incidence and Prevalence Collaborators. Global, regional, and national incidence, prevalence, and years lived with disability for 354 diseases and injuries for 195 countries and territories, 1990-2017: a systematic analysis for the global burden of disease study 2017. Lancet 2018;392:1789-858.

5 Nederlands Huisartsen Genootschap. Niet-traumatische knieklachten, 2016. Available: https://www.nhg.org/standaarden/ samenvatting/niet-traumatische-knieklachten [Accessed 19 Jun 2019].

6 National Institute for Health \& Clinical Excellence. Osteoarthritis: the care and management of osteoarthritis in adults. London, 2014.

7 Fernandes L, Hagen KB, Bijlsma JWJ, et al. EULAR recommendations for the non-pharmacological core management of hip and knee osteoarthritis. Ann Rheum Dis 2013;72:1125-35.

8 Bannuru RR, Osani MC, Vaysbrot EE, et al. OARSI guidelines for the non-surgical management of knee, hip, and polyarticular osteoarthritis. Osteoarthritis Cartilage 2019;27:1578-1589.

9 Kolasinski SL, Neogi T, Hochberg MC, et al. 2019 American College of Rheumatology/Arthritis Foundation guideline for the management of osteoarthritis of the hand, hip, and knee. Arthritis Care Res 2020;72:149-62.

10 Smink AJ, van den Ende CHM, Vliet Vlieland TPM, et al. "Beating osteoARThritis": development of a stepped care strategy to optimize utilization and timing of non-surgical treatment modalities for patients with hip or knee osteoarthritis. Clin Rheumatol 2011;30:1623-9.

11 Basedow M, Esterman A. Assessing appropriateness of osteoarthritis care using quality indicators: a systematic review. $J$ Eval Clin Pract 2015;21:782-9.

12 Eyles JP, Hunter DJ, Bennell KL, et al. Priorities for the effective implementation of osteoarthritis management programs: an OARSI international consensus exercise. Osteoarthritis Cartilage 2019;27:1270-9.

13 Mainz J. Defining and classifying clinical indicators for quality improvement. Int J Qual Health Care 2003;15:523-30.

14 Donabedian $\mathrm{A}$. The quality of medical care. Science 1978;200:856-64.

15 Campbell SM, Cantrill JA. Consensus methods in prescribing research. J Clin Pharm Ther 2001;26:5-14.

16 Schäfer W, van den Berg M, Boerma W. Taakprofielen van huisartsen in Nederland en Europa [English: Job profiles of general practitioners in the Netherlands and Europe], 2016. Available: https://www.henw. org/artikelen/taakprofielen-van-huisartsen-nederland-en-europa [Accessed 25 Aug 2020].

17 Patterson BM, Draeger RW, Olsson EC, et al. A regional assessment of Medicaid access to outpatient orthopaedic care: the influence of population density and proximity to academic medical centers on patient access. J Bone Joint Surg Am 2014;96:e156.

18 Ridic G, Gleason S, Ridic O. Comparisons of health care systems in the United States, Germany and Canada. Mater Sociomed 2012;24:112-20.

19 Marshall MN, Shekelle PG, McGlynn EA, et al. Can health care quality indicators be transferred between countries? Qual Saf Health Care 2003;12:8-12.

20 Petrosyan Y, Sahakyan Y, Barnsley JM, et al. Quality indicators for care of osteoarthritis in primary care settings: a systematic literature review. Fam Pract 2018;35:151-9.

21 Edwards JJ, Khanna M, Jordan KP, et al. Quality indicators for the primary care of osteoarthritis: a systematic review. Ann Rheum Dis 2015;74:490-8.

22 Moher D, Liberati A, Tetzlaff J, et al. Preferred reporting items for systematic reviews and meta-analyses: the PRISMA statement. BMJ 2009;339:b2535.

23 Piligrimiene Z, Buciuniene I. Different perspectives on health care quality: is the consensus possible? In: Economics of engineering decisions, 2008: 104-11.

24 Campbell SM, Braspenning J, Hutchinson A, et al. Research methods used in developing and applying quality indicators in primary care. BMJ 2003;326:816-9.

25 Fitch K, Bernstein SJ, Aguilar MD. The RAND/UCLA appropriateness method user's manual. RAND, 2001. 
26 Shekelle PG, MacLean CH, Morton SC, et al. Assessing care of vulnerable elders: methods for developing quality indicators. Ann Intern Med 2001;135:647-52.

27 Wenger NS, Roth CP, Shekelle P, et al. Introduction to the assessing care of vulnerable elders-3 quality indicator measurement set. J Am Geriatr Soc 2007;55:S247-52.

28 reported Anot. Assessing care of vulnerable elders-3 quality indicators. J Am Geriatr Soc 2007;55:S464-87.

29 Pencharz JN, MacLean CH. Measuring quality in arthritis care: the arthritis Foundation's quality indicator set for osteoarthritis. Arthritis Rheum 2004;51:538-48.

30 Østerås N, Garratt A, Grotle M, et al. Patient-reported quality of care for osteoarthritis: development and testing of the osteoarthritis quality indicator questionnaire. Arthritis Care Res 2013;65:1043-51.

31 MacLean $\mathrm{CH}$. Quality indicators for the management of osteoarthritis in vulnerable elders. Ann Intern Med 2001;135:711-21.

32 MacLean CH, Pencharz JN, Saag KG. Quality indicators for the care of osteoarthritis in vulnerable elders. J Am Geriatr Soc 2007;55:S383-91.

33 MacLean $\mathrm{CH}$, Saag KG, Solomon DH, et al. Measuring quality in arthritis care: methods for developing the arthritis Foundation's quality indicator set. Arthritis Rheum 2004;51:193-202.

34 Barber CE, Patel JN, Woodhouse L, et al. Development of key performance indicators to evaluate centralized intake for patients with osteoarthritis and rheumatoid arthritis. Arthritis Res Ther 2015;17:322.

35 Blackburn S, Higginbottom A, Taylor R, et al. Patient-reported quality indicators for osteoarthritis: a patient and public generated selfreport measure for primary care. Res Involv Engagem 2016;2:5

36 Asch SM, McGlynn EA, Hogan MM, et al. Comparison of quality of care for patients in the Veterans health administration and patients in a national sample. Ann Intern Med 2004;141:938-45.

37 Doubova SV, Perez-Cuevas R. Quality of care for hip and knee osteoarthritis at family medicine clinics: lessons from Mexico. Int J Qual Health Care 2015;27:125-31.

38 Hardcastle AC, Mounce LTA, Richards SH, et al. The dynamics of quality: a national panel study of evidence-based standards. Health Serv Deliv Res 2015;3:1-128.

39 Moore A. Quality of Care for General Medical Conditions: Chapter 17. In: Osteoarthritis treatment. RAND Corporation, 2000.

40 Steel N, Melzer D, Shekelle PG, et al. Developing quality indicators for older adults: transfer from the USA to the UK is feasible. Qual Saf Health Care 2004;13:260-4.

41 Smith KL, Soriano TA, Boal J. Brief communication: national qualityof-care standards in home-based primary care. Ann Intern Med 2007;146:188-92.

42 Saliba D, Solomon D, Rubenstein L, et al. Quality indicators for the management of medical conditions in nursing home residents. J Am Med Dir Assoc 2004;5:297-309.

43 Jansen MJ, Hendriks EJ, Oostendorp RAB, et al. Quality indicators indicate good adherence to the clinical practice guideline on "Osteoarthritis of the hip and knee" and few prognostic factors influence outcome indicators: a prospective cohort study. Eur J Phys Rehabil Med 2010;46:337-45.

44 Peter WF, van der Wees PJ, Hendriks EJM, et al. Quality indicators for physiotherapy care in hip and knee osteoarthritis: development and Clinimetric properties. Musculoskeletal Care 2013;11:193-202.

45 Wierenga PC, Klopotowska JE, Smorenburg SM, et al. Quality indicators for in-hospital pharmaceutical care of Dutch elderly patients: development and validation of an ACOVE-based quality indicator set. Drugs Aging 2011;28:295-304.

46 Østerås N, Tveter AT, Garratt AM, et al. Measurement properties for the revised patient-reported osteoarthritis quality indicator questionnaire. Osteoarthritis Cartilage 2018;26:1300-10.

47 Vandenberghe H, Van Casteren V, Jonckheer P, et al. Quality of care assessment using GPs' electronic patient records: do we need data from home visits? Stud Health Technol Inform 2004;110:35-41.

48 Broadbent J, Maisey S, Holland R, et al. Recorded quality of primary care for osteoarthritis: an observational study. Br J Gen Pract 2008;58:839-43.

49 Grypdonck L, Aertgeerts B, Luyten F, et al. Development of quality indicators for an integrated approach of knee osteoarthritis. $J$ Rheumatol 2014;41:1155-62.

50 Suter LG, Barber CE, Herrin J, et al. American College of rheumatology white paper on performance outcome measures in rheumatology. Arthritis Care Res 2016;68:1390-401.

51 Wang X, Oo WM, Linklater JM. What is the role of imaging in the clinical diagnosis of osteoarthritis and disease management? Rheumatology 2018;57:iv51-60.

52 Zhang W, Moskowitz RW, Nuki G, et al. OARSI recommendations for the management of hip and knee osteoarthritis, part II: OARSI evidence-based, expert consensus guidelines. Osteoarthritis Cartilage 2008;16:137-62.

53 Ostermann J, Brown DS, de Bekker-Grob EW, et al. Preferences for health interventions: improving uptake, adherence, and efficiency. Patient 2017;10:511-4.

54 Campbell SM, Braspenning J, Hutchinson A, et al. Research methods used in developing and applying quality indicators in primary care. Qual Saf Health Care 2002;11:358-64.

55 Wensing M, Elwyn G. Research on patients' views in the evaluation and improvement of quality of care. Qual Saf Health Care 2002;11:153-7.

56 Agency for Healthcare Research and Quality. Six domains of health care quality, 2018. Available: https://www.ahrq.gov/talkingquality/ measures/six-domains.html [Accessed 16 Mar 2021].

57 National Quality Forum. Measures, reports \& tools, 2021. Available: https://www.qualityforum.org/Measures_Reports_Tools.aspx [Accessed 12 Mar 2021].

58 National Institute for Health \& Clinical Excellence. Standards and indicators, 2021. Available: https://eur01.safelinks.protection. outlook.com/?url=https:\%2F\%2Fwww.nice.org.uk\%2Fstandardsand-indicators\%23: :text\%3DNICE\%2520indicators\% 2520 measure\%2520outcomes\%2520that\%2Cuse\%2520outside\% 2520 of\%2520the $\% 2520$ QOF\&data $=04 \% 7$ C01\%7Ci.arslan $\%$ 40erasmusmc.nl\%7C393c688ea3e9406c317b08d8dfac6fc5\% 7C526638ba6af34b0fa532a1a511f4ac80\%7C0\%7C1\% 7C637505279001099828\%7CUnknown\%7CTWFpbGZsb3d8ey JWljoiMC4wLjAwMDAiLCJQljoiV2luMzliLCJBTil6lk1haWwiLCJXVC I6Mn0\%3D\%7C2000\&sdata=zEY7XU5ZluwOIFWhFACIUzO43HYo bUxsMyNGT1w2UXg\%3D\&reserved=0 [Accessed 03 Mar 2021].

59 Strömbeck B, Petersson IF, Vliet Vlieland TPM, et al. Health care quality indicators on the management of rheumatoid arthritis and osteoarthritis: a literature review. Rheumatology 2013;52:382-90.

60 Hochberg MC. Quality measures in osteoarthritis. Clin Exp Rheumatol 2007;25:102-6.

61 Moher D, Liberati A, Tetzlaff J, et al. Preferred reporting items for systematic reviews and meta-analyses: the PRISMA statement. PLoS Med 2009;6:e1000097. 